\title{
El cambio de las concepciones y emociones sobre la enseñanza a través de ciclos de mejora en el aula: un estudio con profesores universitarios de ciencias
}

\author{
Rafael Porlán, Gabriela Delord, Soraya Hamed y Ana Rivero \\ Universidad de Sevilla, Departamento de Didáctica de las Ciencias, Sevilla, España. (correo-e: rporlan@us.es; \\ gcattani1@us.es; sha@us.es; arivero@us.es)
}

Recibido Dic. 24, 2019; Aceptado Feb. 28, 2020; Versión final Mar.26, 2020, Publicado Ago. 2020

\begin{abstract}
Resumen
Este trabajo analiza la evolución de las concepciones y emociones sobre la enseñanza de 16 profesores universitarios de ciencias que han participado en un curso de formación docente centrado en Ciclos de Mejora en el Aula. La metodología se ha basado en técnicas de análisis del contenido de un cuestionario abierto, previo a la formación, y de un informe de síntesis, posterior a la misma. Los resultados muestran que los participantes experimentaron un cambio de modelo de enseñanza, inicialmente centrado en el docente y en la materia, hacia uno centrado en el aprendizaje activo de los estudiantes. También indican que los cambios en las concepciones y en las prácticas de enseñanza promovieron emociones positivas hacia la docencia, y que el cambio de actitud de los estudiantes fue relevante en este proceso. Como conclusión se afirma que el curso formativo ha provocado mejoras significativas en el modelo docente de los participantes.
\end{abstract}

Palabras clave: modelos de enseñanza; educación superior; desarrollo emocional; concepciones sobre la enseñanza

\section{Changes in teaching conceptions and emotions through classroom improvement cycles: a study with university science professors}

\begin{abstract}
This work analyzes the progression of teaching conceptions and emotions among sixteen university science professors who participated in an instructor training course focusing on the Classroom Improvement Cycles. The methodology is based on content analysis techniques from an open questionnaire taken prior to the training course and from a summary report after the course. The results indicate that the participants experienced changes in their teaching that was initially focused on the instructor and subject matter to then become more focused on their students' active learning. Moreover, the results indicate that changes in conceptions and teaching also involved emotional changes and that the student factor is relevant in this process. In conclusion, it is confirmed that the training course has led to significant changes in the participants' teaching model.
\end{abstract}




\section{INTRODUCCIÓN}

Las universidades tienen el reto de cambiar la orientación de la enseñanza desde enfoques centrados en el docente y en la materia a enfoques centrados en el aprendizaje activo (Acosta et al., 2015). Este cambio es posible si se ponen en marcha estrategias formativas adecuadas. Hay evidencias de que los programas de orientación constructivista y organizados en torno a la reflexión sobre la práctica promueven cambios significativos en las concepciones y actuaciones docentes en el ámbito universitario (Briceño et al., 2012; Gibbs y Coffey, 2004; Tardif et al., 2012). También es conocido que resulta insuficiente examinar únicamente los aspectos cognitivos en los procesos de cambio, sin prestar atención a los emocionales, pues se hallan indisolublemente unidos (Cross y Hong, 2011). En este sentido, los autores de este artículo participamos en el Programa de Formación e Innovación Docente del Profesorado (FIDOP) de la Universidad de Sevilla, que responde a las características mencionadas.

La estrategia particular del programa se basa en la puesta en marcha de "Ciclos de Mejora en el Aula" (CIMA) que comentaremos más adelante. Las evaluaciones de los programas existentes se centran más en conocer la satisfacción de los participantes que en investigar el cambio de los docentes al finalizar la formación (Stes et al., 2010). Este trabajo analiza el cambio de los participantes en el programa mencionado, en relación con cuatro variables: el modelo de enseñanza, la secuencia y orden de las actividades, la adaptación o "ajuste" de la enseñanza al aprendizaje real de los estudiantes y las emociones.

Para mejorar la enseñanza es necesario tomar conciencia, analizar y cuestionar los guiones de acción (script) que habitualmente se aplican en clase. Estos guiones han sido interiorizados de forma tácita y en cierta medida están ocultos a la conciencia (Porlán et al., 2010). Difícilmente se puede cambiar aquello que no se reconoce. Por tanto, es imprescindible analizar la propia práctica docente para comprender sus fortalezas y debilidades. Una buena manera de analizar un fenómeno es "modelizarlo", es decir representarlo explícitamente (mental y gráficamente), destacando los elementos esenciales que lo constituyen y sus interacciones (Schwarz et al., 2009).

La utilidad de los modelos es amplia, pero destacaremos dos esenciales: 1) ayudan a la interpretación de un fenómeno, al dotarlo de estructura y organización, evitando así una representación indiferenciada o reduccionista (en el caso de la docencia, es frecuente considerar que los únicos responsables del fracaso en el aprendizaje son los estudiantes) y 2) promueven, en el caso de fenómenos que implican la intervención humana, una toma de decisiones más rigurosa (Justi, 2006). Justi y Gilbert (2002) establecen un itinerario de progresión a la hora de trabajar con modelos: a) aprender modelos ya elaborados; b) aprender a aplicarlos, revisarlos y reconstruirlos y c) aprender a elaborar modelos nuevos. En nuestro caso, añadimos un último nivel, adecuado para los fenómenos que requieren de la intervención humana (como ocurre con la enseñanza), en el que que se elaboran modelos descriptivos sobre la realidad ("lo que es") y modelos prescriptivos sobre el futuro ("lo que debería ser").

La mayoría de los docentes universitarios desean que sus estudiantes participen, sean críticos y se responsabilicen de sus tareas, y viven con frustración la realidad contraria. Estos deseos, sin embargo, son incompatibles con los modelos habituales de enseñanza, que centran el protagonismo en la materia ya elaborada. Cuando el docente modeliza su práctica habitual y su práctica ideal, puede descubrir estas contradicciones y estar en mejores condiciones para afrontarlas. Sin embargo, es preciso tener en cuenta que mientras los modelos reales están contextualizados, y por tanto condicionados por el medio, los ideales son independientes del contexto. Esta diferente naturaleza puede crear dificultades para un diálogo productivo entre ellos. Por tanto, es conveniente la elaboración y experimentación de un modelo mediador ("modelo posible") que facilite la transición entre lo real y lo ideal (figura 1).

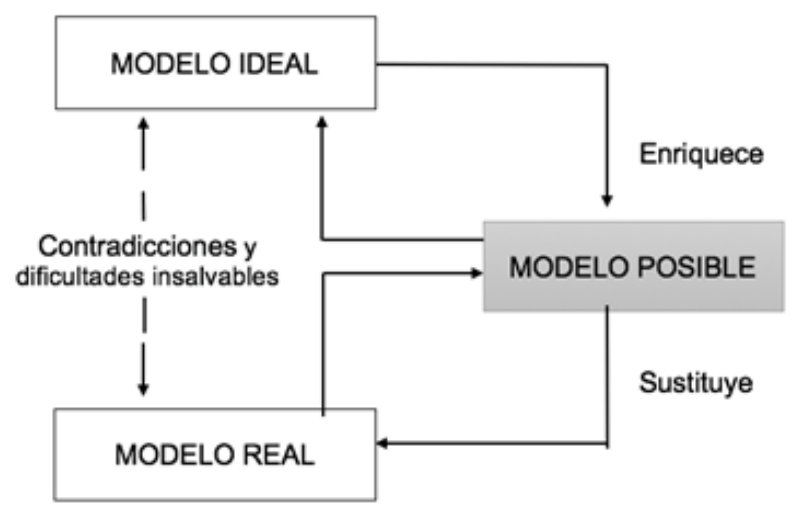

Fig. 1: Relaciones entre el modelo real de enseñanza, el ideal y el posible 


\section{Modelizar la práctica docente}

Los modelos de enseñanza en el ámbito de la Educación Superior han sido caracterizados en la literatura. Así, Postareff y Lindblom-Ylänne (2008), a partir de entrevistas a 71 docentes, consideran que existen dos grandes modelos en la enseñanza universitaria: el centrado en el profesor y en la materia (mayoritario) y el centrado en el estudiante y el aprendizaje (minoritario). Gargallo et al. (2007), a partir de las respuestas de 326 docentes al cuestionario CEMEDEPU (Cuestionario de Evaluación de la Metodología Docente y Evaluativa de los Profesores Universitarios), detectan 4 enfoques. Identifican los dos grandes modelos mencionados como extremos de un continuo, y presentan dos modelos intermedios en función de la intensidad con que se aproximan a uno $u$ otro.

Por último, en el caso de los profesores de ciencias, Briceño et al. (2012), en un estudio con 20 sujetos, describen un modelo mayoritario basado en la transmisión lineal del contenido a los estudiantes. Este enfoque, centrado en el profesor, se describe como una forma de enseñar en la que los estudiantes son receptores pasivos de la información, alcanzando niveles superficiales de aprendizaje. El enfoque centrado en el estudiante, por su parte, considera la enseñanza como una forma de facilitar los procesos de aprendizaje activo e investigativo de los estudiantes (Porlán, 2018; Postareff y Lindblom-Ylänne, 2008; Valderrama y Valderrama, 2014). Para Gargallo et al. (2007), el primero busca la reproducción de los saberes, mientras que el segundo su construcción por los estudiantes. Además de estos dos enfoques, como hemos dicho, se discute en la literatura la existencia de uno o más modelos intermedios. Trigwell y Prosser (2004), por ejemplo, toman en consideración solo los dos modelos mencionados, basándose en los resultados obtenidos con el cuestionario ATI (Inventario de Enfoques de Enseñanza).

\section{Secuencia y orden de las actividades}

En el proceso de modelizar la práctica es necesario considerar una unidad de análisis más concreta: las actividades que organizan el tiempo en el aula. El grado de coherencia entre lo que pensamos y lo que hacemos viene determinado, en parte, por cómo transferimos un modelo a un contexto concreto en términos de actividades (guiones de acción). La revista International Journal of Science Education dedicó un número monográfico en 2004 a las secuencias de actividades, destacándose en los trabajos incluidos la capacidad de dichas secuencias para superar la brecha entre la teoría proveniente de la investigación y las prácticas en el aula (Méheut y Psillos, 2004).

El conocimiento docente mayoritario se basa en rutinas automatizadas vinculadas a contextos, que se activan involuntariamente y que suelen responder a una orientación centrada en la materia. Para avanzar hacia un modelo centrado en el estudiante, pero ajustado al contexto y a las posibilidades del docente ("el modelo posible"), es necesario traducirlo a secuencias de actividades concretas coherentes con él. Este diseño consciente permite generar nuevos esquemas de acción que impiden la activación de los automatismos, prevaleciendo un guion de la clase con sentido, en el que se sabe por qué y para qué se hace lo que se hace. Ya no vale una organización simple basada solo en el orden de los temas, pues, al incorporar la perspectiva del aprendizaje, lo importante es qué ha de hacerse y en qué orden para que tenga sentido para el que aprende y facilite su progresión (Duschl et al., 2011).

Alcanzar un aprendizaje profundo implica el desarrollo de diversas dimensiones en los estudiantes (Bitter y Loney, 2015): construcción del contenido; pensamiento crítico; resolución de problemas; comunicación eficaz; trabajo colaborativo y metacognición. Para favorecerlo, los estudiantes deben experimentar los procedimientos característicos del trabajo científico (National academies of sciences, engineering and medicine, 2020), entre los que destacan la investigación, la modelización, el contraste y la argumentación (Couso et al., 2020). Teniendo en cuenta esto, el modelo ideal centrado en el aprendizaje y alineado con el constructivismo requiere de una secuencia de actividades que a grandes rasgos debe incluir: a) actividades de toma de conciencia y argumentación de las concepciones de los estudiantes ante retos con sentido para ellos (en forma de problemas, proyectos, casos...); b) actividades de contraste entre iguales para promover el máximo nivel de desarrollo que los estudiantes pueden conseguir por sí mismos; c) actividades de contraste con información externa a los estudiantes (bibliográfica, experimental, audiovisual, etc.), que sirvan de andamiaje para su progresión y que entren en competencia con sus concepciones y d) actividades de síntesis, generalización, aplicación y comunicación de los aprendizajes alcanzados. Estos cuatro tipos de actividades pueden ser ordenados en secuencias flexibles, con bucles y retroalimentaciones, y con formas diferentes de empezar y acabar el proceso (Duschl et al, 2011; Marcelo-García et al, 2011). Por tanto, cuando hablamos de orden y secuencia, nos referimos a una visión compleja que admite caminos alternativos y esquemas de acción no encorsetados, pero siempre guiados por el objetivo de hacer avanzar el aprendizaje profundo de los estudiantes (Giné y Parcerissa, 2003; Zabala y Arnau, 2007). 


\section{La enseñanza como un proceso de adaptación al aprendizaje}

La enseñanza como adaptación al aprendizaje ("adaptive instruction”) es una de las características esenciales de una docencia efectiva y ha dado lugar a una importante línea de investigación basada en la descripción, análisis y reformulación de las progresiones de aprendizaje de los estudiantes ("learning progression") (Duschl et al., 2011; Porlán, 2018). Allen et al. (2013) destacan que los resultados de las investigaciones sobre docentes efectivos, muestran como una característica común que adaptan su enseñanza al aprendizaje de los estudiantes. Esta interesante relación entre una enseñanza adaptada al aprendizaje y las progresiones de los estudiantes ha sido enfatizada por Corcoran et al. (2009), quienes consideran que el estudio de las progresiones puede jugar un papel central en el cambio necesario de la enseñanza. Estos autores destacan tres beneficios concretos: a) proporciona una base rigurosa para el diseño de la enseñanza; b) aporta elementos valiosos para una evaluación formativa, pues informa de los niveles de progresión de los estudiantes y facilita la intervención del docente y c) permite el diseño de planes de estudio alineados con las progresiones de los estudiantes.

La transición desde modelos centrados en el docente y en la materia hacia modelos centrados en el aprendizaje requiere de una co-evolución de naturaleza constructivista. Los estudiantes han de incorporarse a un proceso de cambio real, poniendo a prueba sus concepciones a la luz de los argumentos teóricos y/o los datos empíricos que les aporta la secuencia de actividades diseñada por el docente y, al mismo tiempo, los docentes han de adoptar una visión investigadora, poniendo a prueba sus hipótesis didácticas sobre la progresión de los estudiantes y sobre la secuencia de trabajo en el aula que sea más adecuada para impulsarla. Como venimos diciendo, ambos procesos no son lineales y previsiblemente presentan estadios intermedios. Smith et al. (2010) se refieren a los niveles intermedios de una progresión como "escalones" que permiten enlazar los niveles inferiores y superiores con una adecuada secuencia de enseñanza diseñada por el docente. En nuestro caso hablamos de "escaleras de aprendizaje y evaluación" para referirnos a los itinerarios de progresión de los estudiantes y también de los profesores (Porlán, 2017).

\section{Las consecuencias emocionales de los procesos de cambio docente}

Sabemos que cognición y emoción son dos dimensiones inseparables que se retroalimentan. Es tal la naturaleza de esta relación que el poder de restricción o de activación entre ellas puede llegar a ser determinante en los procesos de cambio (Zembylas, 2007). Las emociones suelen catalogarse en positivas y negativas, entendiendo estos puntos como extremos de un continuo. En relación con la enseñanza, Badía (2016) recoge como emociones positivas habituales en los docentes el cuidado, la confianza y el afecto por los estudiantes, así como la satisfacción, alegría, seguridad y placer por la enseñanza. Por su parte, las emociones negativas más habituales son la rabia y decepción hacia los estudiantes, así como el estrés, frustración e impotencia hacia la actividad docente. Algunos trabajos señalan que son más frecuentes las emociones positivas en los docentes con enfoques centrados en el aprendizaje y las negativas en los enfoques centrados en la enseñanza (Badía et al. 2014; Trigwell, 2012).

Por otro lado, es importante destacar que esta interacción se enmarca en relaciones institucionales. Las estructuras de poder, la presión del contexto y las repercusiones que esto tiene en la auto-imagen y en la necesidad de reconocimiento hacen aún más fuerte las influencias mutuas (Kelchtermans, 2005). Particularmente, es conocida la escasa valoración de la actividad docente frente a la investigadora en las universidades españolas, debido a los procesos de evaluación del profesorado de cara a su promoción. Así, mientras en la docencia el factor fundamental es el número de años de dedicación -sin tener en cuenta otros criterios relacionados con la calidad-, en la investigación se necesita acreditar numerosos aspectos definidos con precisión (publicaciones, proyectos de investigación, estancias, etc.). La contradicción, por tanto, entre la dedicación a la docencia y la poca valoración de la misma, genera sentimientos de frustración cuando la única fuente de retroalimentación emocional (los estudiantes) no cubren las expectativas de los docentes (Saunders, 2013). Este autor, en su trabajo sobre el papel de las emociones en el cambio del profesorado, describe los siguientes estadios: a) el docente tiene poco interés por la innovación, aunque se siente frustrado por la poca implicación de los estudiantes; b) siente interés por la innovación, pero está preocupado por las posibilidades de implementarla y siente inseguridad por la valoración que puedan hacer los estudiantes y los colegas; c) muestra satisfacción, pero también preocupación, por el cambio en el aprendizaje de los estudiantes; d) necesita trabajar con otros para mejorar los procesos de aprendizaje de los estudiantes; y e) encuentra satisfacción profesional haciendo modificaciones importantes en sus clases.

Desde nuestro punto de vista, un buen estado emocional activa la cognición y viceversa, sin embargo, en ambas dimensiones existen variables internas y externas que bloquean el proceso; se trata de una relación compleja, en la que, según los casos, puede ser más útil incidir en uno u otro polo de la relación para desactivar las situaciones de restricción. Podemos decir, en definitiva, que hay componentes emocionales y cognitivos, y dimensiones externas e internas, en los obstáculos para el cambio (Bizquerra, 2009) (figura 2). 
En esta investigación describimos los cambios cognitivos y emocionales de sujetos que participan en un proceso de formación voluntario, amparado institucionalmente, que fomenta el sentido de pertenencia a un colectivo innovador y que pretende revalorizar la docencia como una actividad de alto nivel académico.

\section{METODOLOGÍA}

La metodología se presenta en cinco subsecciones: 1) contexto de la investigación; 2) participantes en el estudio; 3) problemas e hipótesis iniciales; 4) categorías y niveles de progresión y 5) instrumentos y técnicas de análisis.

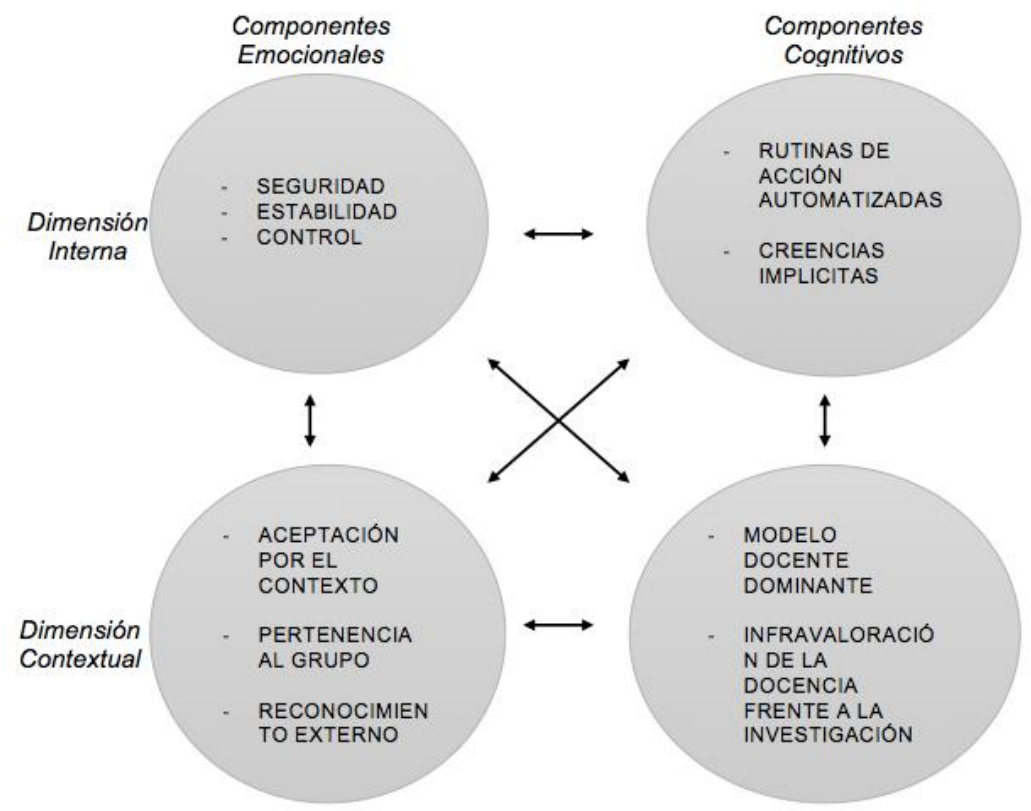

Fig. 2: Diferentes dimensiones que obstaculizan la evolución docente

\section{Contexto de la Investigación}

El objetivo del programa FIDOP es la formación docente del profesorado universitario, favoreciendo un modelo de enseñanza acorde con las evidencias emanadas de la investigación. La estrategia formativa se basa en la realización de Ciclos de Mejora en el Aula (CIMA) de progresiva amplitud y complejidad en el seno de una comunidad de aprendizaje (Porlán, 2017; Rodríguez-Pérez, 2019). La realización de un CIMA implica lo siguiente: a) descripción, modelización y análisis de la práctica habitual, del modelo de enseñanza deseable y del modelo de mejora que cada participante considera "posible"; b) diseño de un número de horas de clases siguiendo el modelo posible y una secuencia de actividades coherente con él; c) experimentación de la secuencia de actividades y seguimiento de la misma a través de un diario de reflexión de uso exclusivo de los participantes; d) análisis crítico del desarrollo de las clases, del aprendizaje alcanzado por los estudiantes y de las fortalezas y debilidades de la experiencia y e) toma de decisiones sobre mejoras a introducir en el siguiente cima y en la práctica habitual. De esta manera, se incorporan a la docencia procedimientos habituales de la investigación (Chocarro et al., 2013).

El programa FIDOP tiene 2 fases en las que se participa de manera voluntaria. En la primera, de iniciación, los docentes asisten al Curso General de Docencia Universitaria (CGDU) de 50 horas presenciales y 40 no presenciales a lo largo de varios meses. El curso se oferta 5 veces al año. En este curso, eminentemente práctico, participan 20 profesores de cualquier especialidad, edad, experiencia y rango académico. Durante el CGDU los participantes tienen que diseñar, experimentar y evaluar dos CIMA, el primero para 4 horas de clases y el segundo para 8. Las sesiones presenciales sirven para el análisis en común de los pasos mencionados, bajo la orientación de un formador experto que promueve el aprendizaje colaborativo y aporta elementos de contraste y reflexión basados en la innovación e investigación docente. En la fase posterior, los participantes se pueden incorporar a la Red permanente de Formación e Innovación Docente (REFID), en un equipo de su área de conocimiento, dinamizado por un colega con más experiencia innovadora. En la red se siguen realizando CIMA cada vez de mayor amplitud temporal hasta abarcar una asignatura completa. Cada año los participantes presentan una publicación que sintetiza el CIMA realizado y se edita como una Monografía (https://editorial.us.es/es/detalle-libro/720118/ciclos-de-mejora-en-el-aula-ano-2019). 


\section{Participantes en el estudio}

El estudio se realizó con los docentes de Ciencias, entendidas en un sentido amplio, que participaron en el CGDU durante el curso 2017/18. Se trata de 16 profesores cuyas características se presentan en la tabla 1.

\section{Problemas e hipótesis iniciales}

Los problemas de este investigación son: ¿En qué sentido cambian las concepciones y las emociones sobre la enseñanza de los docentes de ciencias que han participado en el curso, en la perspectiva de una enseñanza centrada en la actividad del estudiante?, ¿Qué cambios se producen en las categorías: modelo de enseñanza, secuencia y orden de las actividades y adaptación de la enseñanza a los estudiantes?

Tabla 1: Características de los participantes investigados

\begin{tabular}{|c|c|c|c|}
\hline & Asignatura Ciclo de Mejora & Edad & Género \\
\hline 2 & Química & 35 & Mujer \\
\hline 4 & Anatomía & 52 & Hombre \\
\hline 6 & Cálculo infinitesimal & 27 & Hombre \\
\hline 7 & Óptica & 27 & Hombre \\
\hline 9 & Anatomía & 31 & Mujer \\
\hline 10 & Podología & 39 & Hombre \\
\hline 11 & Casos clínicos & 38 & Hombre \\
\hline 12 & Farmacología & 54 & Mujer \\
\hline 14 & Física & 33 & Mujer \\
\hline 23 & Bioquímica & 44 & Mujer \\
\hline 31 & Fundamentos de ciencias & 37 & Mujer \\
\hline 33 & Fisiología & 37 & Mujer \\
\hline 39 & Algebra & 51 & Hombre \\
\hline 40 & Anatomía & 58 & Mujer \\
\hline 46 & Estadística & 31 & Mujer \\
\hline 48 & Masoterapia & 37 & Mujer \\
\hline
\end{tabular}

¿Cómo influyen estos cambios en sus emociones sobre la propia actividad docente y sobre la actitud de los estudiantes? Por nuestra experiencia en la formación e investigación docente, considerábamos que los profesores comenzarían el curso con concepciones coherentes con la enseñanza centrada en el docente. Posteriormente, esperábamos que la experiencia de los CIMA provocaría una transición hacia modelos más centrados en el aprendizaje. Sin embargo, dado los aportes de la bibliografía, que indican que estos cambios requieren tiempo (Gunckel et al., 2018), nos parecía que la evolución de los docentes tendrían un límite, de tal manera que la tendencia mayoritaria sería la de favorecer la participación activa de los alumnos en torno a la resolución de problemas, pero sin llegar a una concepción abierta del aprendizaje final, predominando aún una visión cerrada y única de los contenidos de aprendizaje. Todo ello acompañado de dos tipos de emociones: al principio, negativas respecto a los estudiantes ("que no se implican") y a su propia docencia y, al final, positivas en relación con los estudiantes, debido a un cambio de actitud de los mismos, y con su enseñanza ("sorpresa", "satisfacción" e incluso "entusiasmo").

\section{Categorías y niveles de progresión}

Partimos de un sistema constituido por cuatro categorías: el modelo de enseñanza, la secuencia y orden de las actividades, la adaptación a la progresión del aprendizaje y el cambio de las emociones. Para las tres primeras se definieron tres niveles o estadios: a) el nivel esperado antes de empezar el curso (N1), coherente con un enfoque centrado en el profesor; b) el nivel esperado al final del curso (N2), coherente con una visión simplificada del constructivismo basada en la resolución de problemas cerrados y c) el nivel de referencia de los investigadores (N3), coherente con un modelo centrado en el aprendizaje y basado en el constructivismo. Este sistema de categorías se ha elaborado en base a estudios previos desarrollados con profesores en formación inicial (Martín del Pozo et al., 2011; Porlán et al., 2011; Rivero et al., 2011 y 2017), adaptados a este estudio en Educación Superior (tabla 2). Para el análisis de las emociones, se estableció un sistema de categorías que nos permitiese clasificarlas teniendo en cuenta si eran positivas o negativas y si se referían a los estudiantes o a su propia enseñanza (tabla 5). 


\section{Instrumentos y técnicas de análisis}

Los instrumentos que han servido para conocer las concepciones y emociones de los sujetos han sido: El cuestionario inicial de preguntas abiertas sobre Concepciones Docentes del Profesorado Universitario (CDPU) y el Informe Final que se realizó un mes después de acabado el curso, y que sintetiza el diseño, la práctica y la evaluación del segundo CIMA realizado durante el mismo. Ambos instrumentos abarcan tres grandes dimensiones (enseñanza, contenidos y evaluación), analizándose en este trabajo solo las concepciones relativas a la primera. El cuestionario ha sido sometido a diversas medidas de validez y confiabilidad. Fue evaluado por 10 expertos en formación del profesorado y en metodología de investigación y por 10 docentes universitarios de ciencias. Cada ítem debía ser puntuado por los evaluadores del cuestionario entre 1 (menor pertinencia del ítem) y 5 (mayor pertinencia). Se revisaron todos los ítems con menos de 4 puntos y se tuvieron en cuenta las formulaciones alternativas de los evaluadores. Las preguntas del cuestionario inicial analizadas en este estudio son las que aparecen en la tabla 4. Para los informes finales, las indicaciones sobre su estructura interna están en la tabla 5. En este caso se ha analizado el contenido completo del informe, pues las alusiones a las categorías predefinidas pueden aparecer en diferentes apartados del mismo

Tabla 2: Categorías y niveles hipotéticos de progresión del estudio

\begin{tabular}{llll}
\hline Categoría & $\begin{array}{l}\text { Nivel 1 (esperado al } \\
\text { comenzar el curso) }\end{array}$ & Nivel 2 (esperado al final del curso) & $\begin{array}{l}\text { Nivel 3 (deseable según los } \\
\text { aportes de la investigación) }\end{array}$ \\
\hline Modelo de & Modelo transmisivo centrado & Modelo basado en la resolución de & Modelo constructivista e \\
enseñanza & en el profesor y en la & $\begin{array}{l}\text { problemas cerrados. Transición } \\
\text { intre el centrado en la materia y el } \\
\text { materia. }\end{array}$ & $\begin{array}{l}\text { investigativo. Centrado en el } \\
\text { estudiante y en el aprendizaje. }\end{array}$ \\
& $\begin{array}{l}\text { Protagonismo de los alumnos } \\
\text { limitado por los contenidos } \\
\text { acabados y únicos. }\end{array}$
\end{tabular}

\begin{tabular}{|c|c|c|c|}
\hline $\begin{array}{l}\text { Secuencia } \\
\text { y orden de } \\
\text { las } \\
\text { actividades }\end{array}$ & $\begin{array}{l}\text { El orden viene determinado } \\
\text { por la lógica del contenido }\end{array}$ & $\begin{array}{l}\text { El orden de las actividades pretende } \\
\text { corregir o/y substituir las ideas de } \\
\text { los estudiantes por el conocimiento } \\
\text { verdadero (dichas ideas son errores } \\
\text { y no concepciones alternativas). }\end{array}$ & $\begin{array}{l}\text { El orden de las actividades } \\
\text { pretende favorecer la evolución } \\
\text { de las ideas alternativas de los } \\
\text { estudiantes a través de procesos } \\
\text { de investigación, orientados por } \\
\text { el docente. }\end{array}$ \\
\hline $\begin{array}{l}\text { Enseñanza } \\
\text { adaptada a } \\
\text { los } \\
\text { estudiantes }\end{array}$ & $\begin{array}{l}\text { No hay adaptación de la } \\
\text { enseñanza ni al nivel de } \\
\text { partida de los estudiantes, ni } \\
\text { a su progresión durante las } \\
\text { clases. }\end{array}$ & $\begin{array}{l}\text { Hay adaptación inicial al nivel de } \\
\text { partida de los estudiantes, pero no a } \\
\text { la progresión durante las clases. }\end{array}$ & $\begin{array}{l}\text { La enseñanza se adapta a la } \\
\text { progresión de los estudiantes al } \\
\text { principio y durante las clases. Se } \\
\text { pretende ayudarles a superar las } \\
\text { dificultades de aprendizaje y a } \\
\text { construir mejores } \\
\text { interpretaciones de los } \\
\text { fenómenos investigados. }\end{array}$ \\
\hline
\end{tabular}

Tabla 3: Preguntas analizadas del cuestionario inicial

\section{PREGUNTAS DEL CUESTIONARIO INICIAL ANALIZADAS EN ESTE ESTUDIO}

1. Describe y analiza cuál es tu práctica habitual, contando como es una clase tipo. Céntrate en los detalles y conductas más significativas y en las emociones sentidas, tanto positivas como negativas. Analiza las creencias que están asociadas a dichas emociones

2. Vuelve sobre el relato anterior y representa y argumenta en un gráfico el modelo metodológico habitual de tus clases. Para la representación distingue las fases del modelo con algún símbolo. Une con flechas el itinerario más frecuente seguido en clase. Procura que el tamaño de los símbolos refleje la cantidad de tiempo de cada fase

3. ¿Qué actividades concretas sueles realizar y en qué orden? Argumenta qué sentido y utilidad tiene cada una de ellas para el aprendizaje de los alumnos

4. Si todas las condiciones fueran favorables, representa y argumenta cuál sería tu modelo metodológico ideal (o deseable). Describe y analiza las dificultades y obstáculos que encuentras para llevarlo a cabo

5. ¿Por qué crees que esta metodología es mejor que la habitual en relación con el aprendizaje de los estudiantes?

6. Dadas las circunstancias en que se desarrolla tu docencia, y teniendo en cuenta el modelo ideal descrito, ¿Qué modelo de mejora de la enseñanza ves "posible" aplicar en el CIMA? 
Tabla 4: Estructura de los Informes Finales elaborados por los sujetos

ESTRUCTURA DEL INFORME FINAL

1. Breve descripción del contexto de la intervención (titulación, asignatura, características de los estudiantes, condiciones del espacio y cualquier otra variable relevante para la experiencia)

2. Principios didácticos argumentados que han guiado el CIMA experimentado

3. Mapa de contenidos y problemas argumentado que describe la temática abordada y su estructura (interacciones fundamentales)

4. Modelo de enseñanza "posible" argumentado que ha guiado el CIMA y la secuencia de actividades programada para llevarlo a la práctica

5. Relato de las sesiones, describiendo y analizando el clima de trabajo, la actuación propia, el desarrollo real de las actividades, los avances y dificultades encontradas, etc.

6. Evaluación del aprendizaje de los estudiantes, comparando sus conocimientos iniciales y finales con "escaleras de aprendizaje y evaluación"

7. Evaluación del diseño experimentado, indicando posibles mejoras para un próximo CIMA

8. Conclusiones: ¿Qué aspectos se pretenden incorporar a la práctica docente habitual?

9. Referencias

El tratamiento de los datos se ha realizado a través del análisis del contenido (Krippendorff, 2004; Mayring, 2014), siguiendo los siguiente pasos: a) incorporación de las respuestas al cuestionario y del contenido de los informes al programa Atlas.ti (v. 8); b) localización de unidades de información (UI) relacionadas con las categorías y c) clasificación de cada Ul, según su contenido, en una de las cuatro categorías y en el nivel de progresión correspondiente para las tres primeras; y d) codificación de cada UI (sujeto, no de orden de la UI, categoría, nivel e instrumento). Las UI que no encajaban con ninguno de los niveles previstos provocaron la definición de un nuevo nivel intermedio entre N1 (enseñanza transmisiva) y N2 (resolución de problemas cerrados), que hemos denominado N1/2 (modelo transmisivo abierto a los estudiantes). En el caso de las UI relacionadas con emociones (cuarta categoría), se han clasificado según su tipo (positivas/negativas) y momento (antes/después) del curso. En el proceso han participado 8 investigadores, analizando cada uno 2 sujetos. Después, se han realizado análisis cruzados entre parejas de investigadores, en los que cada cual ha analizado los sujetos de su pareja y viceversa, incluyendo las propuestas de modelos emergentes y negociando las discrepancias (en este contraste se ha obtenido una coincidencia del $72 \%$ ). Las UI que han generado dudas en una pareja han sido discutidas con otra y, en el contexto de este equipo de 4, es donde se han alcanzado los acuerdos sobre niveles intermedios y se han rechazado las que no tenían consenso (nivel de coincidencia del 87\%). Por último, en cada categoría, se ha cuantificado el número de sujetos que se encuentra en cada nivel antes y después del curso, describiendo así la progresión de la muestra.

\section{RESULTADOS}

Los resultados se presentan por categorías y describen los niveles o estadios de las concepciones de los participantes antes y después de realizar el CGDU. Cada nivel se ilustra con ejemplos de unidades de información.

\section{Modelo de enseñanza antes del curso}

En el cuestionario inicial, en 13 de los 16 participantes predomina un modelo transmisivo centrado en el profesor y en la materia, idéntico al N1 del sistema de categorías. Podemos representarlo gráficamente diferenciando dos fases: una de explicación teórica $(T)$ y otra de práctica $(P)$, basada, principalmente, en ejercicios de aplicación de la teoría o/y en preguntas para comprobar lo aprendido. En el caso de clases prácticas (laboratorios, seminarios...), son explicadas directamente por el profesor y reproducidas por los estudiantes siguiendo instrucciones cerradas. En algunos casos se incluye una fase inicial de introducción a la temática (I) o de aclaración de dudas (D) (figuras 3 y 8).

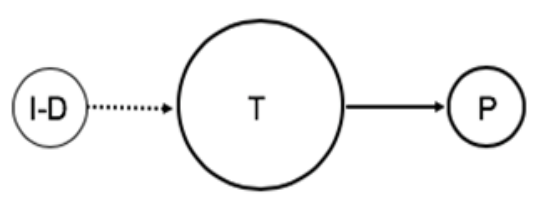

Fig. 3: Modelo de enseñanza mayoritario antes de empezar el curso en las clases teóricas.

Presentamos dos ejemplos de unidades de información: "Primero pongo el índice de la clase sobre una patología de un órgano (I). Luego pongo imágenes de la histología normal del órgano (RP1). A continuación comienzo a explicar la patología, recordando los aspectos teóricos que caracterizan la enfermedad. Ver 
imágenes histológicas del órgano con cáncer es complicado y refrescarles los aspectos teóricos les ayuda a recordar y a poner los conocimientos de otras asignaturas en orden (RT). Posteriormente voy poniendo imágenes a distintos aumentos y voy explicando cómo debe mirar un patólogo (P). Por último, les pongo diapositivas con los aspectos claves que hemos ido viendo (RP2) (figura 4). Respecto a las emociones, suelo comenzar nerviosa e insegura, y el miedo a que lo capten y me juzguen retroalimenta esa sensación, intento llevar siempre la clase bien preparada; intento mostrarme cercana, pero también en ocasiones me ha costado mantener la disciplina (IF9, Anatomía).

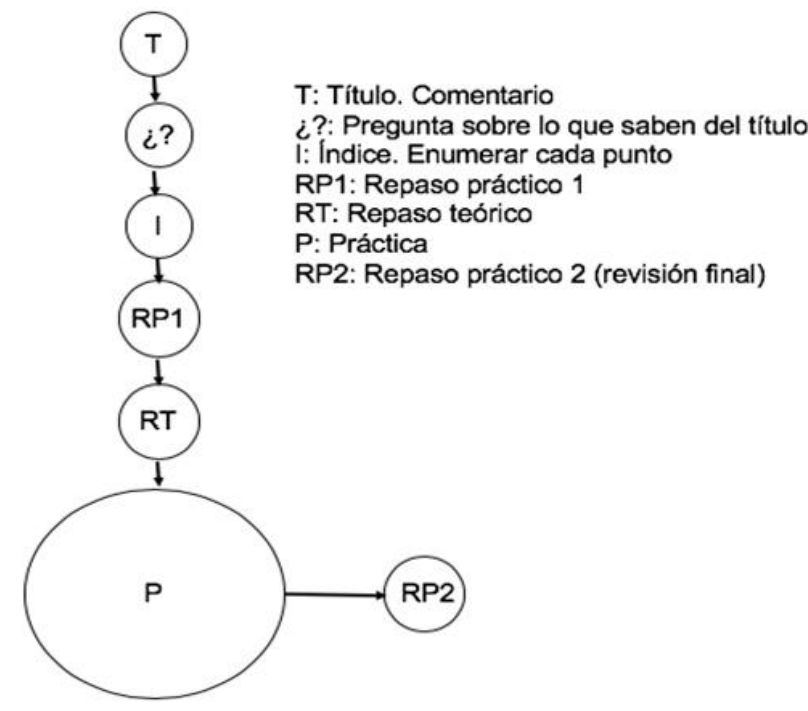

Fig. 4: Modelo de enseñanza del sujeto 9 antes del curso

"Son clases en las que realizo una exposición teórica. El contenido es el establecido por los profesores de la asignatura. Pregunto si tienen dudas y termino la clase volviendo a preguntarles. La asignatura no es atractiva, es árida y poco práctica. Respecto a las emociones, soy yo el que pone pasión e intento hacerles las clases atractivas. En ocasiones reconozco que hasta a mí me resulta pesado" (Cl10, Podología).

Los tres sujetos restantes describen su modelo de enseñanza habitual antes del curso de manera algo diferente al anterior, pues tienen en cuenta, en cierta medida, a los estudiantes. Promueven que participen para que la comprensión de los contenidos sea mejor. Incluyen una fase de introducción a la temática con ejemplos prácticos o/y preguntas sobre el tema que se va a impartir (I). Durante las clases incluyen, además de las clases teóricas $(\mathrm{T})$, actividades prácticas y participativas del tipo: preguntas de los alumnos, explicaciones preparadas y desarrolladas por ellos, etc. (P) (figura 5).

Este nivel, no previsto en el sistema de categorías inicial, lo hemos definido como un nivel de transición entre el N1 ("transmisivo") y N2 ("resolución de problemas cerrados"), definiéndolo como: "transmisivo abierto a los estudiantes" (N1/2).

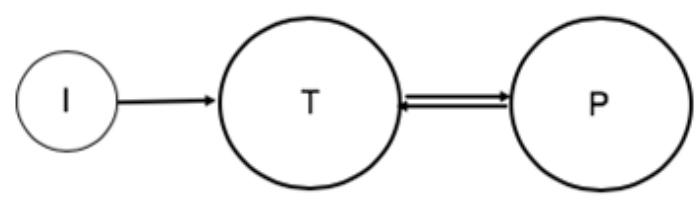

Fig. 5: Modelo de enseñanza transmisivo abierto a los estudiantes, minoritario antes del curso (I: introducción; T: teoría y P: Práctica)

Un sujeto representativo de este modelo es el 40. Aquí un ejemplo de unidad de información: "Sigo dos tipos de clases. Tipo1: expongo la introducción con un ejemplo; desarrollo el tema interrumpido por preguntas mías o que hacen ellos; y les indico lo que tienen que saber. Tipo 2: la exposición la hace un grupo; el contenido lo preparan según un guión que les doy; cada componente expone una parte; la exposición incluye preguntas para que los compañeros contesten; premio la participación; mi papel consiste en aclarar dudas y errores y señalar lo importante; lanzo hipótesis y ejemplos. Emociones: en general siento impotencia, entusiasmo, cansancio, aburrimiento, curiosidad, satisfacción y alegría. Creencias: no vienen motivados, sólo les interesa la nota, no se sienten parte activa del aprendizaje, están educados para recibir, no valoran la importancia del saber" (Cl40, Anatomía). 


\section{Modelo de enseñanza un mes después del curso}

Al acabar el curso, en el informe final sobre el segundo CIMA, solo un sujeto se sitúa en el modelo transmisivo centrado en la materia, aumentan los sujetos con un modelo transmisivo abierto a los alumnos N1/2 (6) y aparecen 9 cuyo modelo incorpora la resolución de problemas/casos dirigida hacia un final cerrado y único (N2) (figura 8). Por tanto, la muestra evoluciona hacia modelos que empiezan a tener en cuenta el aprendizaje de los alumnos. En su representación vemos (figura 6) una fase inicial centrada en la formulación de problemas (PRO), una segunda de resolución de los problemas a partir de las ideas de los alumnos (IA), una intermedia teórico-práctica para confirmar los aprendizajes correctos y modificar los erróneos (T-P) y una fase final en la que se concluye el trabajo desarrollado (C). En este modelo, sigue presente la idea de que hay un conocimiento acabado y único que los estudiantes deben aprender.

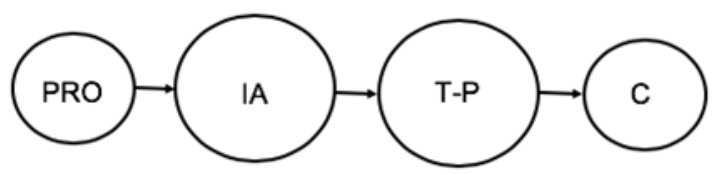

Fig. 6: Modelo de enseñanza basado en la resolución de problemas cerrados (N2) (Pro: problema; IA: ideas alumnos; T-P: teoría-práctica y C: conclusiones)

Veamos un ejemplo (figura 7). "El modelo después del curso consiste en la resolución de preguntas que han trabajado en casa (P). Al iniciar la clase dejo 5 minutos para dudas (D). En este ciclo se incluye el trabajo en grupos $(G)$. Durante 30 minutos leen y debaten sus respuestas a la primera pregunta $(R)$. Tras esto, explico los contenidos erróneos (E). Después, pasamos a la siguiente pregunta. Al final recuerdo la próxima tarea (d). Durante mi exposición la mayoría estaban atentos sin tomar apuntes ique alegría! Mi experiencia es muy satisfactoria. Me ha demostrado que estos cambios son muy beneficiosos para el estudiante" (AF23, Bioquímica).

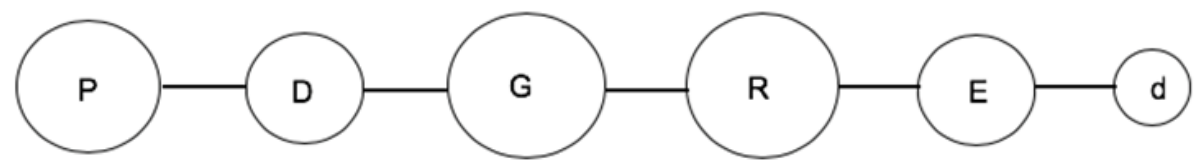

Fig. 7: Modelo del sujeto 23 después del curso. Resolución de problemas cerrados (P: preguntas; D: dudas; G: trabajo en grupos; R: respuestas a la pregunta; E: explicación contenidos erróneos y d: próxima tarea)

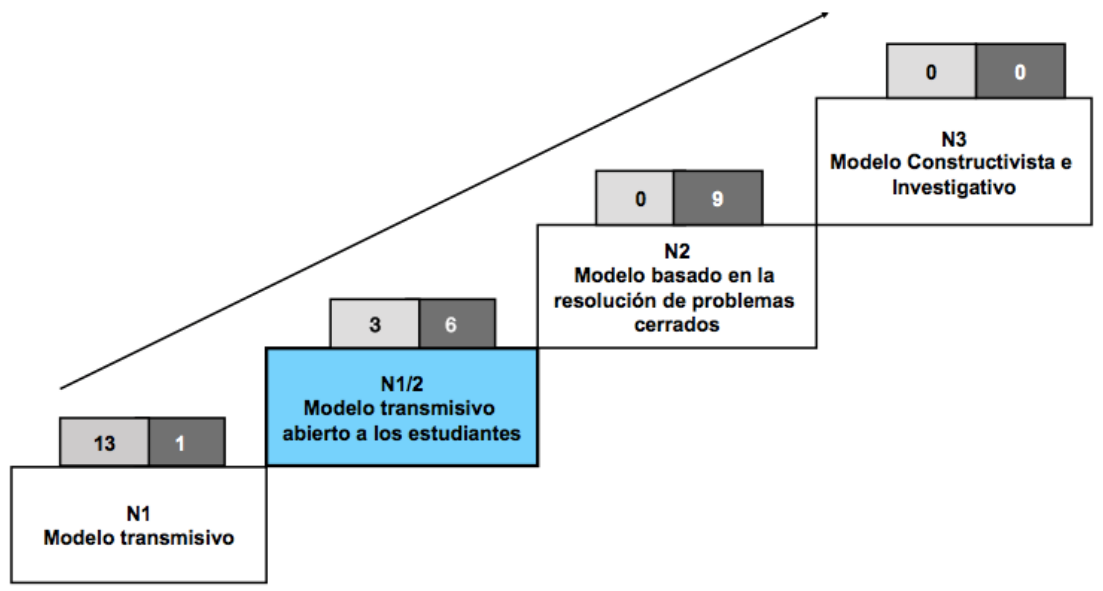

Fig. 8: Progresión de la muestra en relación a la categoría "modelo de enseñanza". En gris claro el número de participantes antes del curso y en gris después del curso. En azul el nuevo nivel resultante del análisis

\section{Secuencia y orden de las actividades antes del curso}

Antes de empezar el curso, 13 de los 16 sujetos ordena la secuencia de trabajo en clase siguiendo exclusivamente la lógica de los contenidos de la materia (N1) (figura 9). La tarea fundamental es la exposición del profesor y, a continuación, algún tipo de actividad breve a realizar por los alumnos para, generalmente, aplicar la teoría. "Cuando llego a clase explico la teoría que corresponde según el orden del temario, preguntando si tienen dudas y poniendo ejemplos. Cuando les pregunto no suelen contestar y me siento impotente por no saber si no me entienden o se están aburriendo. Después hacemos algunas actividades resolviendo ejercicios en los que tenemos que aplicar la teoría" (Cl46, Estadística). 
Al mismo tiempo, hay tres sujetos que proponen una secuencia algo más abierta a los estudiantes: El orden sigue estando influido por la lógica de los contenidos del programa pero "se introducen momentos para dar participación real a los estudiantes", con algunas actividades dirigidas a preguntar a los alumnos sobre sus ideas y experiencias (aunque éstas no se analizan ni se tienen en cuenta posteriormente). El docente no persigue con esto cambiar el modelo transmisivo, sino que intenta optimizarlo. Este modelo, no previsto en la hipótesis inicial, lo hemos situado en la transición entre N1 y N2 (N1/2). Veamos un ejemplo:

"Un orden llevo. Siempre empiezo con una presentación del tema y pregunto sobre conceptos del tema y experiencias relacionadas (...) con el fin de hacerlos partícipes y de que perciban que han tenido algún contacto con lo que veremos. Explorado el tema doy comienzo a la exposición siguiendo el temario. A lo largo de ella voy resolviendo las preguntas que surgen. Si percibo que se desconectan, hago preguntas relacionadas con otras asignaturas, de forma que se establece un debate que me ayuda a recuperarlos. En cuanto a emociones, hay días que tengo más ganas de que acabe la clase que ellos. Intento mantener la paciencia cuando murmuran, pero reconozco que me molesta bastante" (Cl11, Casos clínicos).

\section{Secuencia y orden de las actividades un mes después del curso}

Después del curso, en el informe final, no aparecen declaraciones del nivel 1 en relación con la secuencia de actividades, aumentan los sujetos situados en el nivel 1/2 (6 sujetos) y aparecen 10 sujetos que plantean "secuencias de actividades orientadas a favorecer el aprendizaje de los alumnos" (N2) (figura 9). Se plantean primero actividades para que los alumnos resuelvan problemas con sus propias ideas, después actividades de contraste (que alimenten el debate de los estudiantes) y al final actividades para establecer acuerdos en las que interviene el profesor para corregir errores y resaltar el conocimiento correcto.

"El proceso de experimentación de los ciclos de mejora nos ha llevado a un nuevo modelo. Comenzamos con actividades de "tiempo para los estudiantes" donde, a través de una pregunta intrigante, trazamos el hilo conductor de la sesión. Posteriormente pasamos directamente a la discusión de sus hipotesis y de aquí a la teoría/práctica, dependiendo del tema. La última actividad de repaso permite concluir sobre la pregunta inicial. Los aprendizajes docentes nos han brindado una oportunidad muy valiosa, pues conocer el punto de partida del alumnado, las barreras para su aprendizaje y los conceptos mal entendidos, nos permiten colocarnos a la altura que ellos necesitan" (AF33, Fisiología).

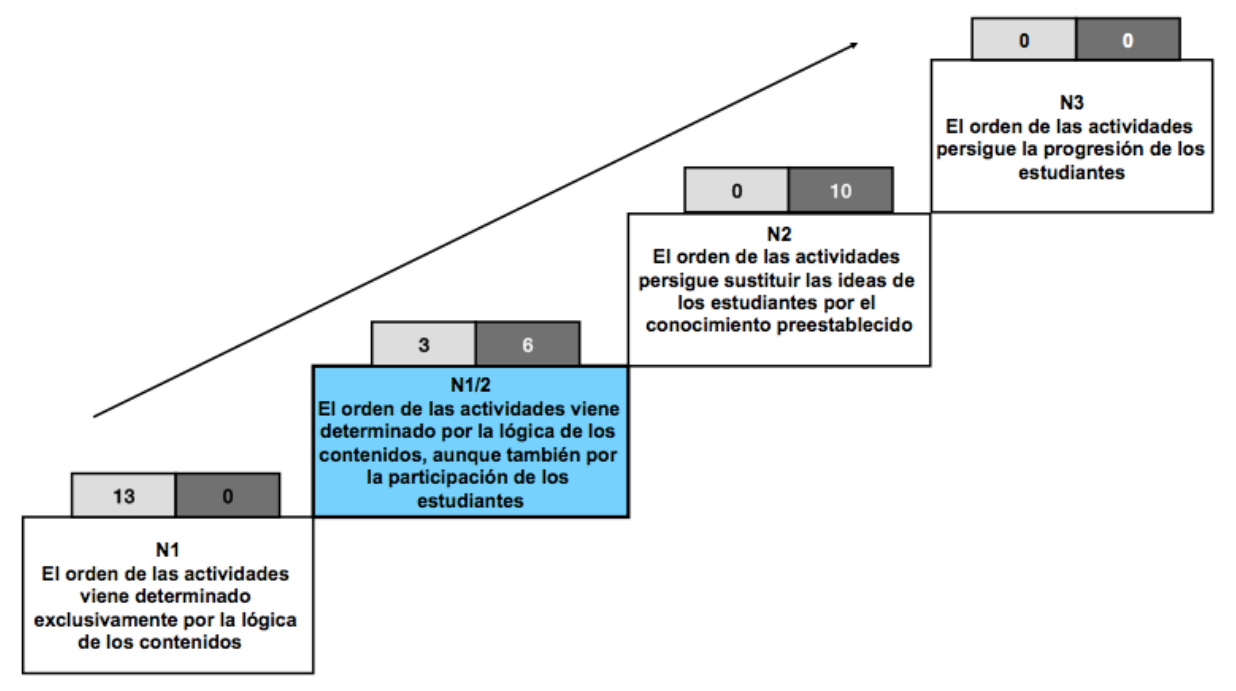

Fig. 9: Progresión de la muestra en relación a la categoría "secuencia y orden de las actividades" antes y después del curso

\section{Enseñanza adaptada a los estudiantes antes del curso}

Antes de empezar el curso todos los docentes describen y analizan sus clases bajo el supuesto de que "la enseñanza es independiente del punto de partida de los estudiantes" (N1). No hay declaraciones que reflejen la idea de que al enseñar debe darse un proceso de adaptación a sus ideas y experiencias o al menos conocer qué nociones manejan y cómo. A veces se les hacen preguntas, se les da tiempo para aclarar dudas o para realizar alguna actividad práctica, pero solo para activar su atención y para comprobar la asimilación o no de los contenidos. 
"Presento el tema y hago un repaso de las clases anteriores. Siento emociones positivas si los alumnos están atentos y muestran curiosidad e interés (las menos veces), y emociones negativas si están dispersos; y pienso: no les motivan mis clases. Imparto la materia con clases expositivas en las que lanzo preguntas o pido experiencias propias a los alumnos. Si participan y contestan de forma adecuada (pocas veces) siento que les gustan mis clases y que soy una buena profesora. Si no participan o contestan de forma incorrecta pienso que son vagos y que me hincho de trabajar y ellos nada. Si son incapaces de relacionar los conceptos, pienso: en el colegio no les han enseñado a pensar" (Cl12, Farmacología).

\section{Enseñanza adaptada a los estudiantes un mes después del curso}

En los informes finales sobre los CIMA experimentados, disminuyen los sujetos con concepciones típicas de $\mathrm{N} 1$ y aparecen 13 sujetos de nivel 2, que adaptan la enseñanza a las ideas iniciales de los alumnos de una manera sistemática (utilizando cuestionarios). Sigue latente la idea de que este tipo de adaptación "sirve fundamentalmente para corregir errores" y para llegar al conocimiento acabado y pre-establecido (figura 10).

"Disfruté mucho de la sesión. Trabajamos el problema 5: ¿Cómo diagnosticamos el cáncer? Les pasé una encuesta tipo Socrative, específica para el aprendizaje previo y final de este contenido. Para mi satisfacción, el $90 \%$ de los estudiantes respondió correctamente las 4 preguntas al final. Fue fantástico ver cómo debatían los pros y contras de cada respuesta (...) Dedicamos el tiempo de clase a debatir, a partir del caso clínico, cuáles eran los factores de los que depende el crecimiento de las neoplasias. Yo corregía directamente los errores durante el debate. Me di cuenta de que había hecho un debate más clínico que nunca. Ahora me doy cuenta de que ha merecido la pena" (AF4, Anatomía).

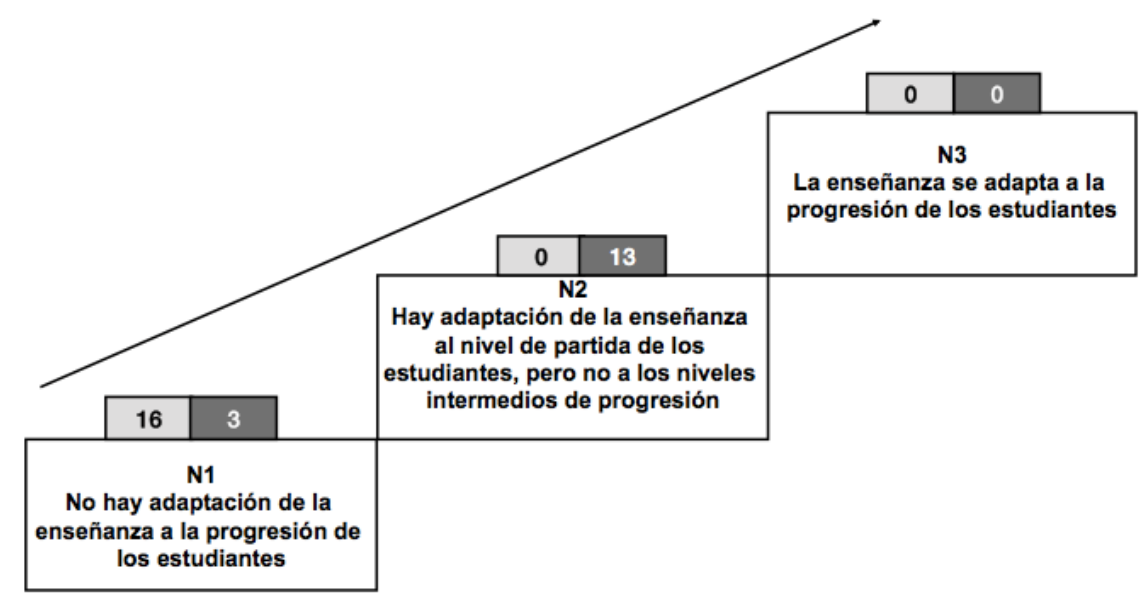

Fig. 10: Progresión de la muestra en relación a la categoría "adaptación de la enseñanza a los estudiantes" antes y después del curso.

\section{Las emociones antes del curso}

Al empezar el curso, los participantes manifiestan más emociones negativas que positivas respecto a sus estudiantes. Así, bastantes manifiestan impotencia y frustración ante la actitud pasiva y desconectada de sus alumnos e inseguridad y miedo ante su posible valoración. Veamos algunas de las unidades de información relacionadas: "Cuando les pregunto no suelen contestar y me siento impotente por no saber si no me entienden o se están aburriendo" (Cl46, Estadística); "Respecto a las emociones, suelo comenzar nerviosa e insegura, y el miedo a que lo capten y me juzguen retroalimenta esa sensación" (Cl10, Podología).

Por otro lado, algunos manifiestan aburrimiento ante las clases poco atractivas y funcionales que están obligados a dar, pero también, en otros casos, alegría y satisfacción con su actividad docente. Estos son dos ejemplos: "En cuanto a emociones, hay días que tengo más ganas de que acabe la clase que ellos" (Cl11, casos clínicos); "Generalmente al comienzo de la clase me siento animado, con ganas de transmitir contenidos y valores" (Cl4, Medicina).

El computo general de unidades de información relacionadas con emociones antes de empezar el curso es de 7 positivas y 15 negativas relativas a los estudiantes y de 15 positivas y 8 negativas en relación con su propia enseñanza (tabla 5), lo que da a entender que se muestran más críticos con los estudiantes que con su propio enfoque docente (en el que, recordemos, predomina casi en exclusiva el nivel $\mathrm{N} 1$ en este momento del curso). 
Tabla 5: Emociones antes y después del curso

\begin{tabular}{|c|c|c|c|c|}
\hline & \multicolumn{2}{|c|}{ Estudiantes } & \multicolumn{2}{c|}{ Enseñanza } \\
\cline { 2 - 5 } & Positiva & Negativa & Positiva & Negativa \\
\hline ANTES & 7 & 15 & 15 & 8 \\
\hline DESPUÉS & 16 & 7 & 25 & 9 \\
\hline
\end{tabular}

\section{Las emociones un mes después del curso}

En las declaraciones emocionales asociadas a este momento predominan claramente las positivas, tanto en relación con la nueva orientación de la enseñanza desarrollada durante el curso ( 25 unidades de información frente a 15 antes del curso), como en relación con los estudiantes (16 frente a 7) (tabla 5). Se expresan sentimientos de "satisfacción y alegría por los cambios producidos en los estudiantes y por su mayor implicación, compromiso y autonomía", así como valoraciones muy entusiastas acerca del tipo de enseñanza implementada. Por ejemplo:

"Disfruté mucho de la sesión. Trabajamos el problema 5: ¿Cómo diagnosticamos el cáncer? Les pasé una encuesta tipo Socrative, específica para el aprendizaje previo y final de este contenido. Para mi satisfacción, el $90 \%$ de los estudiantes respondió correctamente las 4 preguntas al final. Fue fantástico ver cómo debatían los pros y contras de cada respuesta (...) Dedicamos el tiempo de clase a debatir, a partir del caso clínico, cuáles eran los factores de los que depende el crecimiento de las neoplasias. Yo corregía directamente los errores durante el debate. Me di cuenta de que había hecho un debate más clínico que nunca. Ahora me doy cuenta de que ha merecido la pena" (AF4, Anatomía).

\section{DISCUSIÓN}

De acuerdo a nuestras hipótesis, el punto de partida de los participantes coincide mayoritariamente con el enfoque transmisivo centrado en el docente y la materia, al igual que en otros estudios con profesorado universitario (Amundsen y Wilson, 2012; Fernández et al., 2013). Este enfoque responde a una creencia implícita sobre el aprendizaje del tipo: "mente en blanco" o "vaso vacío". Al mismo tiempo, los resultados muestran también la presencia, minoritaria antes del curso, de una variante, no prevista en nuestra hipótesis de partida, que implica una cierta apertura a la participación del estudiante (N1/2). En relación con la categoría modelo de enseñanza, este nuevo nivel se manifiesta por la aparición de una fase motivadora que persigue preparar al estudiante para la transmisión de la teoría (llamar su atención haciéndole preguntas, presentar información para estimular su interés, etc.), y por una relación algo más interactiva entre la teoría y la práctica. La categoría secuencia de actividades se concreta en una organización dependiente del orden lógico de los contenidos, pero con la inclusión de algunas actividades para involucrar a los estudiantes en el desarrollo de la enseñanza. No hemos detectado esta variante, sin embargo, en la categoría enseñanza adaptada a los estudiantes. Interpretamos que se trata de un nivel de transición en el que los participantes han comenzado a tener en cuenta al estudiante, pero aún no cuestionan sus teorías implícitas sobre el aprendizaje. Estos resultados apoyan los presentados por Gargallo et al. (2007) que formulan un modelo de similares características al $\mathrm{N}(1 / 2)$, considerándolo de menor intensidad dentro del enfoque centrado en el profesor y que caracterizan por "hacer uso de algunas actividades complementarias a la explicación (preguntas, análisis de un caso...)" y por "promover las aportaciones de los alumnos aunque sigue siendo fundamental la explicación cerrada de los contenidos".

En las emociones que aparecen al inicio del curso acompañando a las concepciones de nivel N1 (transmisivo), encontramos que son mayoritarias las valoraciones muy negativas sobre los estudiantes pero positivas sobre la propia docencia. Estos resultados difieren de lo que esperábamos y de los resultados del trabajo de Trigwell (2012), obtenidos de 175 docentes a través de dos cuestionarios, uno relacionado con emociones y otro con enfoques de enseñanza, en el que las emociones negativas se presentan asociadas a enfoques de enseñanza centrados en el profesor y las emociones positivas a los enfoques centrados en el estudiante. En nuestro caso, aún predominando claramente un enfoque transmisivo respecto a la enseñanza, los participantes, muestran más emociones positivas que negativas sobre su práctica docente. En cambio, sí son coherentes con los estadios iniciales descritos por Saunders (2013), en los que el docente, aun teniendo cierto interés por la innovación, está conforme con su enseñanza y vuelca su frustración hacia los estudiantes.

Un mes después del curso, la presencia del nivel N1 es muy escasa, el nivel N1/2 aparece con mayor intensidad que en el momento inicial y el nivel mayoritario en las tres categorías es el N2, tal como esperábamos en nuestra hipótesis inicial. En las categorías modelo de enseñanza y secuencia y orden de las actividades, en este N2, las fases de transmisión teórica y de aplicación práctica, características del nivel anterior, ahora se entienden como una única fase donde, de forma teórica o/y práctica, se promueven "actividades de contraste" con los estudiantes. Además, es precedida por otras fases en la que los estudiantes 
expresan y debaten sus ideas ante los problemas o casos planteados y es seguida de una fase en la que el docente confirma y completa las respuestas definitivas a los problemas. En relación con la adaptación de la enseñanza al aprendizaje de los estudiantes, se realiza un ajuste del diseño previo del CIMA a las ideas iniciales de los estudiantes a través de un cuestionario. En este enfoque los docentes superan la teoría implícita del "vaso vacío", reconociendo que los estudiantes tienen ideas previas desde las que interpretan las informaciones procedentes del exterior, pero tienden a caracterizarlas como "errores" a eliminar o sustituir por las ideas correctas.

Es esta última característica la que diferencia claramente el nivel N2 del nivel N3 de referencia, donde la adaptación pretende siempre facilitar la progresión de los estudiantes a partir de actividades de contrastes, contra-argumentación y contra-evidencias relevantes, diseñadas por el docente, desde su dominio profundo de la materia, para abordar las dificultades de aprendizaje específicas que van surgiendo, y siendo los estudiantes los que han de construir por sí mismos el conocimiento. También lo entienden así Gargallo et al. (2007), que diferencian dentro del enfoque centrado en los estudiantes, uno de menor y otro de mayor intensidad. En ambos se promueven las aportaciones de los alumnos (características similares a las de nuestro N2). Sin embargo, mientras en el grupo de mayor intensidad se piensa que el conocimiento es una construcción de los estudiantes que se elabora con la ayuda del profesor, en el grupo de menor intensidad aparecen contradicciones al concebir el conocimiento disciplinar como un referente cerrado del proceso. En el mismo sentido, Garmendia et al. (2014) destacan que los docentes participantes en el programa de formación en que se desarrolló el estudio asumían con cierta rapidez la idea de organizar los contenidos en torno a problemas, pero se resistían a plantearlos "antes de la teoría", desconfiando de que los estudiantes pudieran dar respuesta a los mismos sin disponer previamente del conocimiento correcto.

Postareff y Lindblom-Ylänne (2008) mantienen, sin embargo, que sus resultados no permiten definir con claridad dos enfoques dentro de la orientación centrada en el aprendizaje. Para estos autores, el propósito de la enseñanza debe ser el único criterio para organizar la diversidad de los resultados. Así, si los docentes seleccionan actividades y recursos con la intención de promover un aprendizaje significativo en los estudiantes se categorizan en un enfoque centrado en el aprendizaje; si, por el contrario, las actividades se seleccionan sin tener en cuenta si mejoran o no el aprendizaje de los estudiantes, sino por la lógica del contenido, se categorizan en un enfoque centrado en el profesor y la enseñanza. Estando de acuerdo con esta diferenciación, consideramos que estos autores obvian una segunda cuestión de vital importancia: ¿el aprendizaje que se pretende es un proceso abierto o conduce a un final predeterminado? Es decir, ¿subyace un cierto "absolutismo epistemológico" (para nosotros latente en el nivel 2) o se acepta la progresión real e idiosincrática de los estudiantes (propia del nivel 3)? (Porlán y Rivero, 1998).

Las emociones detectadas después de finalizar el curso son fundamentalmente positivas respecto a los estudiantes y a los nuevos enfoque de enseñanza experimentados, expresadas siempre en relación a los cambios percibidos en los estudiantes, ya sea por su implicación, por la mejora de las relaciones con ellos o por el aprendizaje conseguido. Los participantes en nuestro estudio se sitúan ahora en el estadio que Saunders (2013) describe como de "satisfacción". Parece que experimentar un modelo de enseñanza más centrado en el alumno, con el apoyo de un proceso formativo adecuado, provoca una respuesta positiva en los estudiantes (Gargallo et al., 2015) y esto influye de manera directa en la mejora del estado emocional de los docentes (Trigwell, 2012).

El cambio de los docentes a lo largo del curso ha sido muy importante. Han modificado su orientación desde una centrada en sí mismos y en la materia a otra centrada en el aprendizaje y en los estudiantes, aunque, como esperábamos, no en su versión más compleja. Desarrollar un enfoque como el definido en N3 es difícil en el contexto universitario. Por ejemplo, diseñar y aplicar secuencias de actividades que se vayan adaptando a la progresión continua de los estudiantes es un asunto pendiente en la universidad (Pulido et al., 2009; Salvador et al., 2011). Las dificultades que encuentran los docentes para desarrollar un enfoque centrado en el aprendizaje, son señaladas con claridad por los participantes en el estudio de Nuru y Alafiatayo (2018): "exigencia de enseñar grandes cantidades de contenido", "escasez de tiempo dedicado a la enseñanza" y "culturas académicas que subestiman la docencia".

Al mismo tiempo, Postareff et al. (2008) muestran que el cambio de los enfoques en la enseñanza universitaria es lento. En su estudio, necesitaron un año de formación para detectar efectos positivos en el profesorado, mientras que el periodo aquí analizado ha durado unos 6 meses. En el mismo sentido, Gibbs y Coffey (2004), tras su amplio estudio sobre el cambio de docentes en programas formativos, señalan que se necesitan programas de entre 4 y 18 meses para que se modifique de forma consistente la orientación de la enseñanza. En el estudio de Saunders (2013), al finalizar el primer año de formación, los docentes se situaban en estadios intermedios. No fue hasta finalizar los 4 años del programa, cuando se situaron en los estadios más avanzados donde predominaban las emociones positivas y de seguridad, como sin embargo sí ha ocurrido en nuestro caso con una duración bastante menor. La importancia del cambio detectado en nuestro estudio, a pesar de 
tener un duración intermedia, puede deberse a la estrategia basada en el diseño, experimentación y evaluación de Ciclos de Mejora en el Aula (CIMA).

Esta estrategia ha promovido un debate sobre qué es enseñar y qué es aprender a la hora de modelizar la práctica docente, haciendo aflorar las teorías y esquemas implícitos de los participantes. Diversos estudios resaltan la necesidad de tomar conciencia de dichas concepciones si se quiere cambiar la orientación de la enseñanza (Feixas, 2010; Postereff et al., 2007). Los CIMA han permitido también la formulación explícita de un "modelo posible" de enseñanza, adaptado al contexto, y situado entre lo habitual y lo ideal, reduciendo el estrés asociado a los proyectos de innovación (Saunders, 2013), que bloquea, con frecuencia, los procesos de cambio (Nuru y Alafiatayo, 2018). La idea de hacer lo posible y no lo ideal ha permitido abordar simultáneamente la modelización de la enseñanza, que activa el pensamiento formal, y el diseño de secuencias de actividades concretas, manteniendo la difícil coherencia entre lo abstracto y lo concreto. Ambas tareas han sido abordadas-de manera integrada y coherente, evitando así el efecto de aproximación y alejamiento de lo ideal que detectan Postareff et al. (2008) y que interpretan como resultado de "bajar a la realidad" después de idealizar una alternativa.

\section{CONCLUSIONES}

Este estudio nos ha permitido describir y analizar el cambio de las concepciones y emociones de profesores universitarios de ciencia al participar en un curso de formación basado en la reflexión y experimentación sobre su práctica docente. En relación con los problemas de la investigación, podemos concluir: a) Los participantes en el curso han evolucionado, mayoritariamente, desde una enseñanza centrada en el profesor y la materia a una centrada en los estudiantes y el aprendizaje en las tres categorías cognitivas analizadas, aunque sin alcanzar el modelo de referencia; b) el cambio ha sido bastante similar en las categorías modelo de enseñanza y secuencia de actividades, y algo diferente en la de adaptación de la enseñanza a los estudiantes. A pesar de ello, el cambio presenta coherencia entre las tres categorías; c) los resultados permiten definir cuatro enfoques de enseñanza universitaria: "transmisivo", "transmisivo abierto a los estudiantes" (emergente), basado en la "resolución de problemas cerrados" y "constructivista e investigativo"; d) los cambios en las concepciones y en las prácticas de los docentes han ido acompañados de cambios emocionales positivos, influidos especialmente por una mejora en la actitud e implicación de los estudiantes y e) las emociones de los docentes sobre la práctica pueden ser un buen indicador para valorar los resultados de la formación, aunque es necesario profundizar sobre este aspecto.

En este trabajo debemos señalar dos limitaciones. La participación en el curso fue voluntaria, por lo que es de suponer que los docentes estaban motivados por mejorar su docencia, lo que habrá influido en su evolución. A su vez, no ha sido posible aportar aún evidencias de la observación directa en el aula y de la opinión de los estudiantes. Por ello, los resultados provienen del conocimiento declarativo y de la reflexión de los participantes, aunque no de su comportamiento en la acción. Estos aspectos deben ser tenidos en cuenta en la comparación con otros estudios.

\section{AGRADECIMIENTOS}

Este estudio es parte del Proyecto de I+D+i titulado "La Formación Docente del Profesorado Universitario. Progresos y Obstáculos de los Participantes en un Programa Basado en Ciclos de Mejora de su Práctica" (EDU2016-75604-P), financiado por el Ministerio de Educación y Competitividad del Gobierno de España.

\section{REFERENCIAS}

Acosta, L.A., Abreu, O. y Coronel, M.F., Sistema de formación pedagógica en la Universidad de Otavalo en Ecuador, doi: 10.4067/S0718-50062015000200007, Formación Universitaria, 8(2), 43-52 (2015).

Allen, M.H., Matthews, C.E. y Parsons, S.A., A second-grade teacher's adaptive teaching during an integrated scienceliteracy unit, doi:10.1016/j.tate.2013.06.002, Teaching and Teacher Education, 35, 114-125 (2013).

Amundsen, C., y Wilson, M., Are we asking the right questions? A conceptual review of educational development in higher education, doi: 10.3102/0034654312438409, Review of Educational Research 82(1), 90-126 (2012).

Badía, A., Emociones y sentimientos del profesor en la enseñanza y la formación docente, en C. Monereo (Coord.), Enseñando a enseñar en la universidad, 62-90, Octaedro, Barcelona, España (2016).

Badía. A., Meneses, J. y Monereo, C. University teachers' affective dimension about their teaching: an exploration through the semantic differential technique, doi:10.11144/Javeriana.UPSY13-1.adup, Universitas Psychologica, 13(1), 122 (2014).

Bitter, C., y Loney, E. Deeper learning: improving students outcomes for college, career, and civic life. Education Policy Center at American Institute for Research (2015).

Bizquerra, R., Psicopedagogía de las emociones, Síntesis, Madrid, España (2009). 
Briceño, J.J., Benarroch, A. y Marín, N., Coherencia epistemológica entre ciencia, aprendizaje y enseñanza de profesores universitarios colombianos. Comparación de resultados con profesores chilenos y españoles, doi: https://doi.org/10.5565/rev/ec/v31n2.741, Enseñanza de las Ciencias, 31(2), 55-74 (2012).

Corcoran, T., Mosher F.A. y Rogat, A., Learning progressions in science: An evidence based approach to reform,

Consortium for policy research in education, Report, Philadelphia, USA (2009).

Couso, D., Jiménez, R., Refojo, C. y Sacristán, J., Enseñando ciencia con ciencia, Fundación Lilly y FECYT, Madrid, España (2020).

Cross, D.I. y Hong, J.Y., Beliefs and professional identity: critical construct in examining the impact of reform on the emotional experiences of Teachers, en Advances in teacher emotion research por P.A. Schtz y M.M. Zembylas (Eds.), 273-296, Springer, Dordrecht, USA (2011).

Chocarro de Luis, E., Sobrino, A. y González-Torres, M.C., Scholarship of teaching and learning: un modelo de desarrollo profesional de los profesores universitarios, doi: 10.6018/reifop.16.1.179401, Revista Electrónica Interuniversitaria de Formación del Profesorado, 16(1), 5-14 (2013).

Duschl, R., Maeng, S. y Sezen, A., Learning progressions and teaching sequences: a review and analysis, doi: 10.1080/03057267.2011.604476, Studies in Science Education, 47(2), 123-182 (2011).

Feixas, M., Enfoques y concepciones docentes en la universidad, Relieve, ISSN: 1134-4032, 16(2), 1-27 (2010).

Fernández, I., Guisasola, G. y otros tres autores, ¿Puede la formación tener efectos globales en la universidad? Desarrollo docente, metodologías acticas y currículum hibrido, doi: 10.1174/021037013807532990, Infancia y Aprendizaje, 36(3), 387-400 (2013).

Gargallo, B., Fernández, A. y Jiménez, M.A., Modelos docentes de los profesores universitarios, doi: 10.14201/teri.3256, Teoría de la Educación, 19, 167-189 (2007).

Gargallo, B., Morera, I. y García, E. Metodología innovadora en la universidad. Sus efectos en los procesos de los estudiantes universitarios, doi: 10.6018/analesps.32.1.179871, Anales de Psicología, 31(3), 901-915 (2015).

Garmendia, M., Barragués, J.I. y otros dos autores, Proyecto de formación del profesorado universitario de ciencias, matemáticas y tecnología, en las metodologías de aprendizaje basado en problemas y proyectos, doi: 10.5565/rev/ensciencias.911, Enseñanza de las Ciencias, 32(2), 113-129 (2014).

Gibbs, G. y Coffey, M., The impact of training of university teachers on their seaching skills, their approach to teaching and the approach to learning of their students, doi: 10.1177/1469787404040463, Active Learning in Higher Education, 5(1), 87-100 (2004).

Giné, N., Parcerisa, A. y otros tres autores, Planificación y análisis de la práctica educativa. La secuencia formativa: fundamentos y aplicación, Graó, Barcelona, España (2003).

Gunckel, K., Covitt, B. e I. Salinas, Learning progressions as tools for supporting teacher content knowledge and pedagogical content knowledge about water in environmental systems, doi: 10.1002/tea.21454, Journal of Research in Science Teaching, 55(9), 1-23 (2018).

Justi, R., La enseñanza de las ciencias basada en la elaboración de modelos, Enseñanza de las Ciencias, ISSN: 21746486, 24(2), 173-184 (2006).

Justi, R. y Gilbert, J.K., Modelling teacher's views on the nature of modelling and Implications for the education of modellers, doi: 10.1080/09500690110110142, International Journal of Science Education, 24(4), 369-387 (2002).

Kelchtermans, G. Teachers' emotions in educational reforms: Self-understanding, vulnerable commitment and micropolitical literacy, doi: 10.1016/j.tate.2005.06.009, Teaching and Teacher Education, 21, 995-1006 (2005).

Krippendorff, K., Content analysis: an introduction to its methodology, Sage Publications Inc., California, USA (2004).

Marcelo-García, C., Yot-Domínguez, C. y otros tres autores, Diseñar el aprendizaje en la universidad: identificación de patrones de actividades, Profesorado. Revista de Currículum y Formación de Profesorado, 15(2), 181-198 (2011).

Martín del Pozo, R., Porlán, R. y Rivero, A., The progression of prospective teachers' conceptions of school science content, doi: 10.1007/s10972-011-9233-4, Journal of Science Teacher Education, 22(4), 291-312 (2011).

Mayring, Ph., Qualitative content analysis. Theoretical foundation, basic procedures and software solution, free download via Social Science Open Access Repository SSOAR, (2014).

Méheut, M. y Psillos, D., Teaching-learning sequences: aims and tools for science education research, doi: 10.1080/09500690310001614762, International Journal of Science Education, 26(5), 515-535 (2004).

National Academies of Sciences, Engineering, and Medicine, Changing expectations for the k.12 teacher workforce: policies, preservice education, professional development an the workplace, doi: $10.17226 / 25603$, The National Academies Press, Washington, USA (2020).

Nuru, A.R. y Alafiatayo, B.M., Barriers to incorporating student-centered learning approaches into the teaching and learning of undergraduate Biology in Nigeria, Journal of Science, Technology y Education, ISSN: 2277-0011, 6 (1), 41-52 (2018).

Porlán, R. (Coord.), Enseñanza universitaria. Cómo mejorarla, Morata, Madrid, España (2017). 
Porlán, R., Didáctica de las ciencias con conciencia, doi:10.5565/rev/ensciencias.2795, Enseñanza de las Ciencias, 36(3), 5-22 (2018).

Porlán, R., Martín del Pozo, R. y otros cuatro autores, El cambio del profesorado de ciencias l: marco teórico y formativo, Enseñanza de las Ciencias, 28(1), 31-46 (2010).

Porlán, R., Martín del Pozo, R. y otros cuatro autores, El cambio del profesorado de ciencias II: itinerarios de progresión y obstáculos en estudiantes de magisterio, Enseñanza de las Ciencias, 29(3), 413-426 (2011).

Porlán, R. y Rivero, A., El conocimiento de los profesores, Díada, Sevilla, España (1998).

Postareff, L. y Lindblom-Ylänne, S., Variation in teachers' descriptions of teaching: broadening the understanding of teaching in higher education, doi:10.1016/j.learninstruc.2007.01.008, Learning and Instruction, 18, 109-120 (2008).

Postareff, L., Lindblom-Ylänne, S. y Nevgi, A., A follow-up study of the effect of pedagogical training on teaching in higher education, doi: 10.1007/s10734-007-9087-z, Higher Education, 56, 29-43 (2008).

Pulido, M., De la Torre-Cruz, M. y otros dos autores, Estilos de enseñanza y aprendizaje en el EEES: un enfoque cualitativo, Revista Estilos de Aprendizaje, ISSN: 1988-8996, 4, 156-171 (2009).

Rivero, A., Azcárate, P. y otros tres autores, The progression of prospective primary teachers' conceptions of the methodology of teaching, doi: 10.1007/s10972-011-9233-4, Research in Science Education, 41(5), 739-769 (2011).

Rivero, A., Martín del Pozo, R. y otros tres autores, Cambio del conocimiento sobre la enseñanza de las ciencias de futuros maestros, doi: 10.5565/rev/ensciencias.2068, Enseñanza de las Ciencias, 35(1), 29-52 (2017).

Rodríguez-Pérez, M.V., Reflexión sobre las prácticas educativas que realizan los docentes universitarios: el caso de la Facultad de Educación de UNIMINUTO, doi: 10.4067/S0718-50062019000100109, Formación Universitaria, 12(1), 109120 (2019).

Salvador, L., Argos, J. y otros tres autores, Perfiles de estilos de aprendizaje de los estudiantes universitarios y metodologías docentes, Bordón, Revista de Pedagogía, ISSN: 0210-5934, 63(2), 41-52 (2011).

Saunders, R., The role of teacher emotions in change: experiences, patterns and implications for professional development, doi: 10.1007/s10833-012-9195-0, Journal of Educational Change, 14(3), 303-333 (2013).

Schwarz, C.V., Reiser, B.J. y otros siete autores, Developing a learning progression for scientific modeling: making scientific modeling accessible and meaningful for learners, doi: doi.org/10.1002/tea.20311, Journal of Research in Science Teaching, 46(6), 632-654 (2009).

Smith, C.L., Wiser, M. y Carraher, D.W. Using a comparative, longitudinal study with upper elementary school students to test some assumptions of a learning progression for matter. Paper presented at the annual meeting of the National Association for Research on Science Teaching, Philadelphia, USA (2010).

Stes, A., Min-Leliveld, M. y otros dos autores, The impact of instructional development in higher education: the state-ofthe-art of the research, doi: 10.1016/j.edurev.2009.07.001, Educational Research Review, 5, 25-49 (2010).

Tardif, M., Borges, C y Malo, A., Le vireje reflexif en education. Oú en sommes-nous 30 ans aprés Schön?, De Boeck, París, Francia (2012).

Trigwell, K., Relations between teachers' emotions in teaching and their approaches to teaching in higher education, doi: 10.1007/sl 1251-01 1-9192-3, Instructional Science, 40(3), 607-621 (2012).

Trigwell, K. y Prosser, M., Development and use of the approaches to teaching inventory, doi: 10.1007/s10648-004-00079, Educational Psychology Review, 16, 409-424 (2004).

Valderrama, A.J. y Valderrama, O.J., Trabajo semestral guiado: un buen complemento al estudio y aprendizaje en cursos de Ciencia y de Ingeniería, doi: 10.4067/S0718-50062014000300002, Formación Universitaria, 7(3), 3-10 (2014).

Zabala, A. y Arnau, L., 11 ideas clave: cómo aprender y enseñar competencias, Graó, Barcelona, España (2007).

Zembylas, M., Emotional ecology: the intersection of emotional knowledge and pedagogical content knowledge in teaching, doi: org/10.1016/j.tate.2006.12.002, Teaching and Teacher Education, 23(4), 355-367 (2007). 
